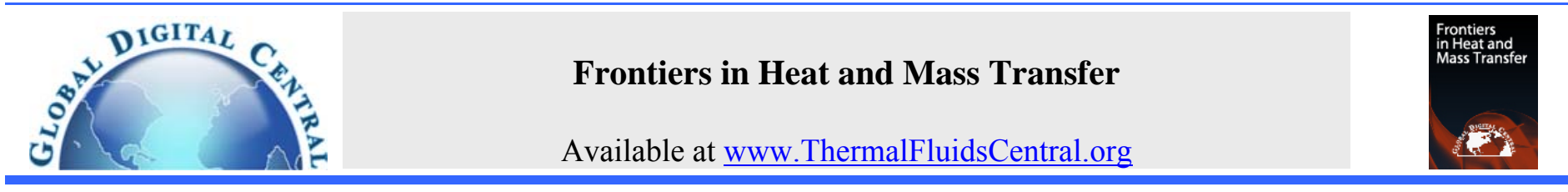

\title{
PERFORMANCE OF ORTHOTROPIC ANNULAR FINS HAVING CONTACT RESISTANCE
}

\author{
Harpreet Kaur Aasi, Vivek Kumar Gaba, Anil Kumar Tiwari and Shubhankar Bhowmick ${ }^{*}$ \\ Department of Mechanical Engineering, National Institute of Technology Raipur (CG)-492010, India
}

\begin{abstract}
Due to low density and low coefficient of thermal expansion, orthotropic materials, namely, the polymer matrix composites are finding their way in many of the engineering application. The present study investigates the performance of the orthotropic annular fin. The thermal conductivity along radial and axial direction is governed by the thermal conductivity ratio $(K)$, which is an important parameter for orthotropic annular fin. The work then numerically examines in two dimensions, the thermal performance of the annular fin at different thermal conductivity ratio $(K)$ for the rectangular profile using the finite difference method. Different convective heat transfer coefficient are considered at the fin sides and the fin tip. The effect of various parameters such as axial Biot number $\left(B i_{s}\right)$, contact Biot number $\left(B i_{c}\right)$, tip Biot number $\left(B i_{e}\right)$, aspect ratio $(b / a)$, thermal conductivity ratio $(K)$ on the efficiency $(H)$ and temperature distribution over the fin surface are presented.
\end{abstract}

Keywords: Thermal conductivity ratio, Polymer material, Orthotropic, Annular fin, Contact Resistance.

\section{INTRODUCTION}

Normally, annular fin analysis is carried out assuming the fin thickness to be negligible as compared to the fin radius. However few studies indicate that for a comparable fin thickness, a two dimensional study better predicts the fin performance as compared to one dimensional analysis. Apart from this, nowadays composite metals are widely used in industrial and commercial application such as compact heat exchanger and air cooled electronics devices and being orthotropic in nature, studies based on isotropic material property assumption for such applications lead to wrongful prediction of the performance. Hence a two dimensional analysis of orthotropic annular fin has to be carried out.

Survey of literature point towards the scarcity of literature pertaining to thermal performance analysis of orthotropic annular fins in two dimensions. Yovanovich et al. (1988) and Mustafa et al. (2011) studied the temperature distribution and heat transfer rate for orthotropic two-dimensional, annular fins subject to convective-tip boundary condition and the contact resistance at the fin base. Dimensionless heat transfer rates are presented and fin efficiency ratio is plotted as a function of Biot numbers and fixed values of geometric parameters. Apart from these, two dimensional studies of annular fins are not found in close sight. The thermal solutions of composite, metallic fins of variable thickness have been reported by Campo and Acosta-Iborra (2009). Heat transfer and temperature distribution equations for longitudinal convectiveradiative porous fins were presented in Hatami and Ganji (2014), SiC and $\mathrm{Si}_{3} \mathrm{~N}_{4}$ are the selected ceramic porous materials, and it was reported that exponential section fin with $\mathrm{Si}_{3} \mathrm{~N}_{4}$ material results into maximum heat transfer. Thermal performance of functionally graded rectangular annular fin has been reported in Aziz and Rahman (2009) and Gaba et al. (2014). The convection heat transfer coefficient was assumed to be a function of both the radial coordinate and the angular speed of the shaft. Aziz and Lopez (2011) studied the heat transfer process in a continuously moving sheet or rod of variable thermal conductivity which loses heat by convection and radiation simultaneously. Aziz and Khani (2011) developed analytical solution for heat transfer in a moving fin of variable thermal conductivity losing heat by both convection and radiation. It was compared with the direct numerical solution to validate the accuracy of the analytical results. Torabi and Yaghoobi (2012) studied heat transfer in a moving fin with variable thermal conductivity losing heat by convection and radiation using Differential transformation method (DTM). The results demonstrate that the DTM is very effective in generating analytical solutions for even highly nonlinear problems.

Aziz and Mujahid (1993) studied the performance of annular fins when its base is subjected to environmental temperatures periodically. Results show that for straight and annular fins the performance of the rectangle shape is the best followed parabolic profile then the least favorable for the triangular shape.

Kang and Look (1997) worked on two dimensional symmetric fins for different values of slope, heat loss and non-dimensional fin length and relationships among these parameters have been discussed. The results reveal that as the slope increases the heat loss decreases and maximum observed the heat loss is for rectangular fins. Lin and Jang (2002) presented the analysis an elliptic fin under the dry, partially wet and fully wet conditions for a range of value for axis ratios, Biot numbers, and air humidifies. It is shown that the fin efficiencies increase as the axis ratio is increased for a particular axis ratio, the efficiency decreases with decrease in fin height or increase in Biot number.

In a recent work, Gaba et al. (2015) reported the parametric study of functionally graded rotating annular fin where in the effect of rotating fin parameter and grading of material on the performance of rectangular annular fin has been investigated.

\section{MATHEMATICAL FORMULATION}

The fin schematic for a two-dimensional model of an orthotropic annular fin is shown in the Fig. 1. In the present work, thermal conductivity ratio $(K)$, being the foremost parameter due to the orthotropic nature of fin 
under study, is defined as the square root of the ratio of thermal conductivity along axial direction $\left(K_{z}\right)$ to radial direction $\left(K_{r}\right)$ and is studied for values ranging between 0.25 to 1.00 as the range typically represents the values of polymeric matrix composite with discontinuous carbon fiber with polymer matrix. Mustafa et al. (2011) investigated orthotropic fins and found that one dimensional fin performance results over predict the two dimensional orthotropic fin results. Some assumptions like homogeneity of material, constant convection coefficient and steady state of fin have been considered while deriving the governing equations.
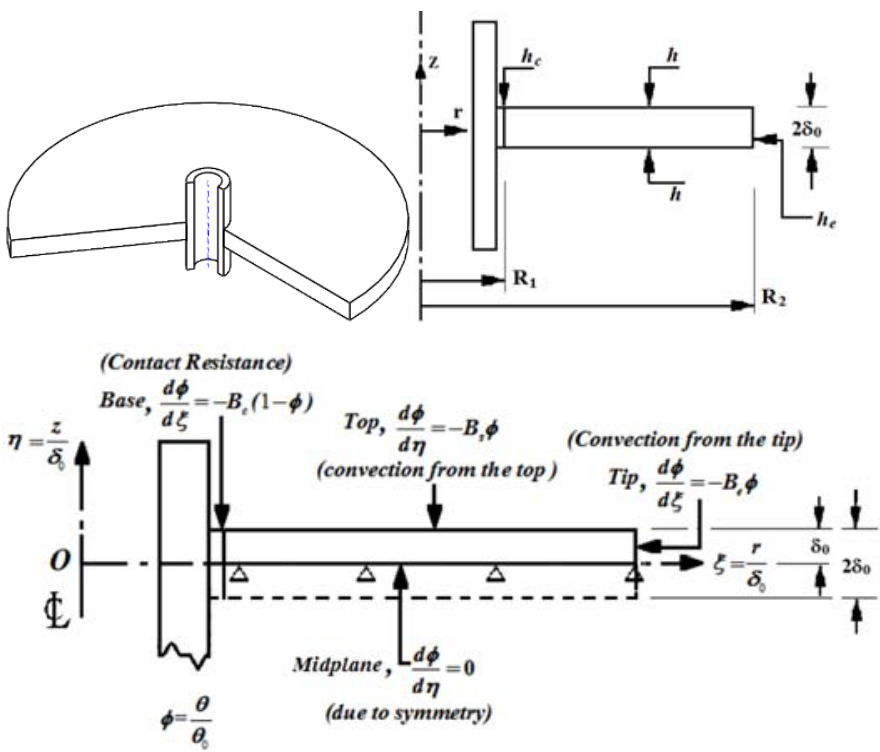

Fig. 1 Sectional isometric view, half sectional front view and boundary conditions of orthotropic annular fin

The governing differential two-dimensional equation in cylindrical coordinates for the excess temperature can be expressed as,

$K_{r}\left(\frac{\partial^{2} \theta}{\partial r^{2}}+\frac{\partial \theta}{r \partial r}\right)+K_{z} \frac{\partial^{2} \theta}{\partial z^{2}}=0$

Here, excess temperature is

$\theta(r, z)=T(r, z)-T_{\infty}$

After normalization with $\xi=\frac{r}{\delta_{0}}, \eta=\frac{z}{\delta_{0}}, \phi=\frac{\theta}{\theta_{0}}$ the governing equation Eq. (1) takes the form:

$\frac{\partial^{2} \phi}{\partial \xi^{2}}+\frac{1}{\xi} \frac{\partial \phi}{\partial \xi}+K^{2} \frac{\partial^{2} \phi}{\partial \eta^{2}}=0$

$K^{2}=\frac{K_{z}}{K_{r}}$

The boundary conditions are schematically shown in Fig.1. Finite difference discretization of the normalized governing equation Eq. (2) and the boundary conditions is as follows:

Internal element discretization:

$\phi_{i, j}=a_{1} \phi_{i+1, j}+a_{2} \phi_{i-1, j}+a_{3}\left(\phi_{i, j+1}+\phi_{i, j-1}\right)$

In Eq. (2),
$a_{1}=\frac{1}{2}\left(\frac{1+A_{1}}{1+A_{2}}\right), a_{2}=\frac{1}{2}\left(\frac{1-A_{1}}{1+A_{2}}\right), a_{3}=\frac{1}{2}\left(\frac{A_{2}}{1+A_{2}}\right)$,

$a_{4}=2 B i_{s} \Delta \xi, a_{5}=2 B i_{c} \Delta \xi a_{6}=2 B i_{e} \Delta \xi$

$A_{1}=\frac{A_{1} \Delta \xi}{2}$

Boundary condition at mid-plane $(\eta=0)$ along radial direction (for all values of $\xi$ ):

$\phi_{i, 1}=a_{1} \phi_{i+1,1}+a_{2} \phi_{i-1,1}+2 a_{3}\left(\phi_{i, 2}\right)$

Boundary condition at top-plane $(\eta=1)$ along radial direction (for all values of $\xi$ ):

$\phi_{i, n y}=\frac{a_{1} \phi_{i+1, n y}+a_{2} \phi_{i-1, n y}+2 a_{3}\left(\phi_{i, n y-1}\right)}{1+a_{3} a_{4}}$

Boundary condition at base along thickness:

$\phi_{1, n y}=\frac{\left(a_{1}+a_{2}\right) \phi_{2, j}+a_{3}\left(\phi_{1, j+1}+\phi_{1, j-1}\right)+a_{2} a_{5}}{1+a_{2} a_{5}}$

Boundary condition at tip along thickness:

$\phi_{n x, j}=\frac{\left(a_{1}+a_{2}\right) \phi_{n x-1, j}+a_{3}\left(\phi_{n x, j+1}+\phi_{n x, j-1}\right)}{1-a_{1} a_{6}}$

Eq. (2) is solved at different nodal points on the discretized grid within the fin domain and temperature distribution over the grid is evaluated using Eqs. (3-7) subject to successive iteration.

\section{RESULT AND DISCUSSION}

The effect of thermal conductivity ratio, aspect ratio, axial and tip Biot numbers on temperature distribution and fin performance is studied and reported in this section. The dependence of dimensionless temperature, $\phi$, on thermal conductivity ratio $(K)$ and aspect ratio $(b / a)$ is analyzed first. In the present work, $K$ ranges from 0.25 to $1.0, b / a$ is varied between 1.1 to $1.6, B i_{s}$ ranges from 0 to $0.5, B i_{c}$ ranges from 0.1 to 10 and $B i_{e}=0$. The present methodology is validated with Mustafa et al. (2011) and results are presented in Tab.1. The results are found to be in good agreement thus establishing the validity of reported results.

Table 1 Validation of the present work

\begin{tabular}{lllll}
\hline$h$ & $K$ & $\begin{array}{l}Q(\mathrm{~W}), \\
\text { Mustafa } \text { et al. } \\
(2011)\end{array}$ & $\begin{array}{l}Q(\mathrm{~W}) \\
\text { (Present work) }\end{array}$ & $\begin{array}{l}\text { Percentage } \\
\text { error }(\%)\end{array}$ \\
\hline 100 & 0.24094 & 20.72 & 20.69 & 0.14 \\
\hline 500 & 0.24094 & 37.30 & 36.88 & 1.12 \\
\hline 100 & 0.96076 & 20.99 & 20.67 & 1.52 \\
\hline 500 & 0.96076 & 38.34 & 37.97 & 0.9 \\
\hline
\end{tabular}

The variation of dimensionless temperature, $\phi$ along $\xi$ and $\eta$ coordinates is studied for the specified range of thermal conductivity ratio $(K)$ and aspect ratio $(b / a)$. The effect of conductivity ratio on temperature distribution over the fin surface in $\xi$ - $\eta$ plane of a given aspect ratio is plotted in contour maps for different $K$ values in Fig. 2, keeping $B i_{c}$ and $B i_{s}$ are constant. It is noted that, increase in orthotropic nature of the fin increases the temperature at the fin surface thus improving the fin performance. 

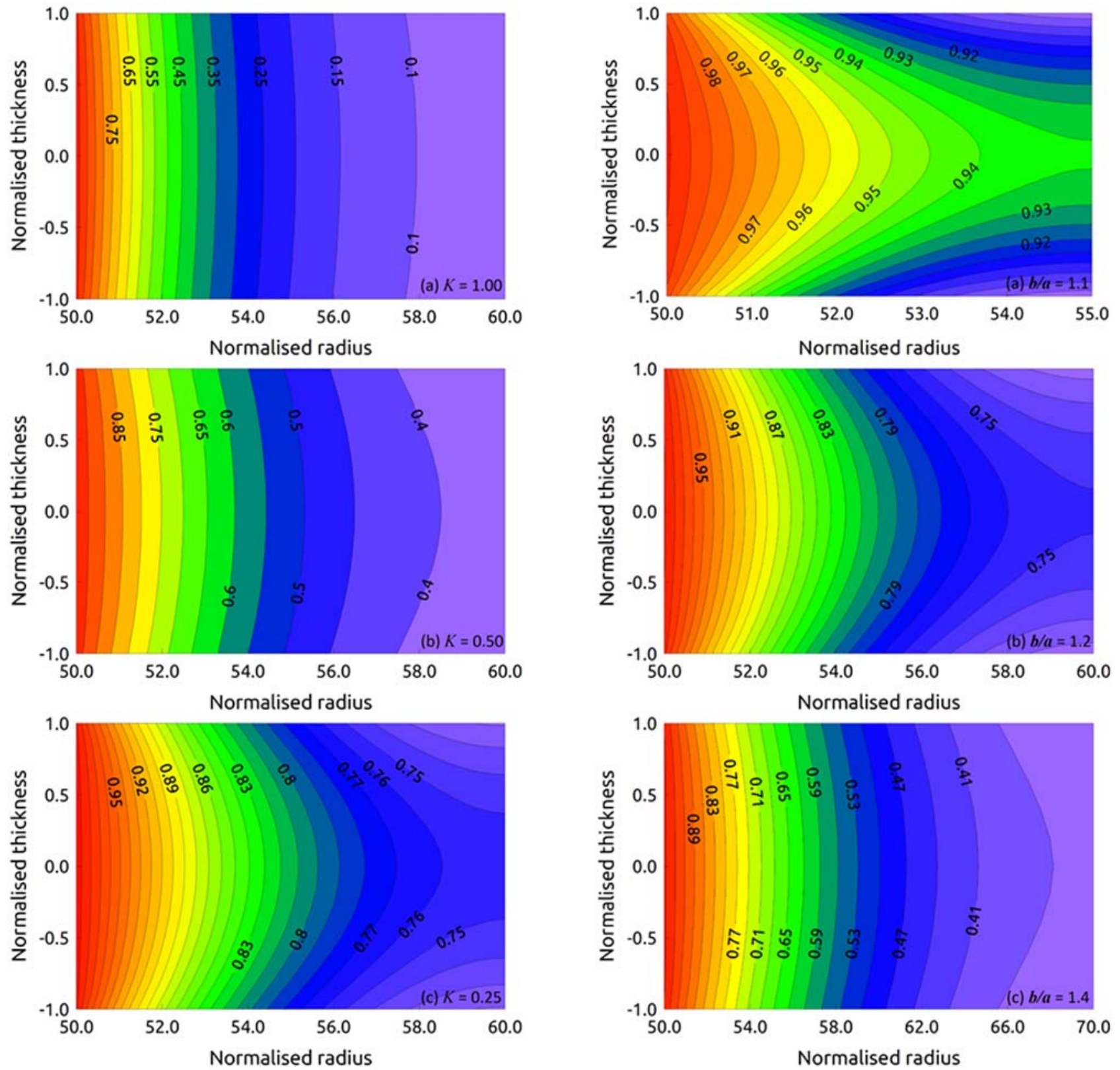

Fig. 2 Temperature distribution over the fin surface in $\xi$ - $\eta$ plane for different aspect ratio $\left(b / a=1.2, B i_{s}=0.1\right.$ and $\left.B i_{c}=5.0\right)$

The effect of aspect ratio on the temperature distribution across the fin surface in $\xi-\eta$ plane is reported in contours plotted in Fig. 3. The plots reveal that as aspect ratio increases the surface temperature decreases and hence has an obvious adverse effect on the fin performance.

A comparison of fin performance $\left(H_{2}\right)$ of the annular fin of orthotropic material response $(K=0.50)$, aspect ratio, $b / a=1.2$ and $B i_{c}=$ 0.1 , thus considering temperature gradient in two dimensions, with efficiency $\left(H_{l}\right)$ of one dimensional annular fin is reported in Fig. 4. It is observed in Fig. 4 that, at lower axial Biot number, performance of the fin based on one dimensional study closely agrees with that obtained by taking into account the orthotropic nature of the fin material. However, as $B i_{s}$ increases, a sharp drop in the efficiency ratio is observed thus establishing the necessity of two dimensional study as one dimensional study tends to over-predict the performance. The results plotted in Fig. 2 and Fig. 3 give a significant insight for the assessment of fin performance and a categorical investigation of the effect of different parameters on fin performance is carried out and reported in Figs 4-7.

Fig. 3 Temperature distribution over the fin surface in $\xi$ - $\eta$ plane for different aspect ratio $\left(K=0.25, B i_{s}=0.1\right.$ and $\left.B i_{c}=5.0\right)$

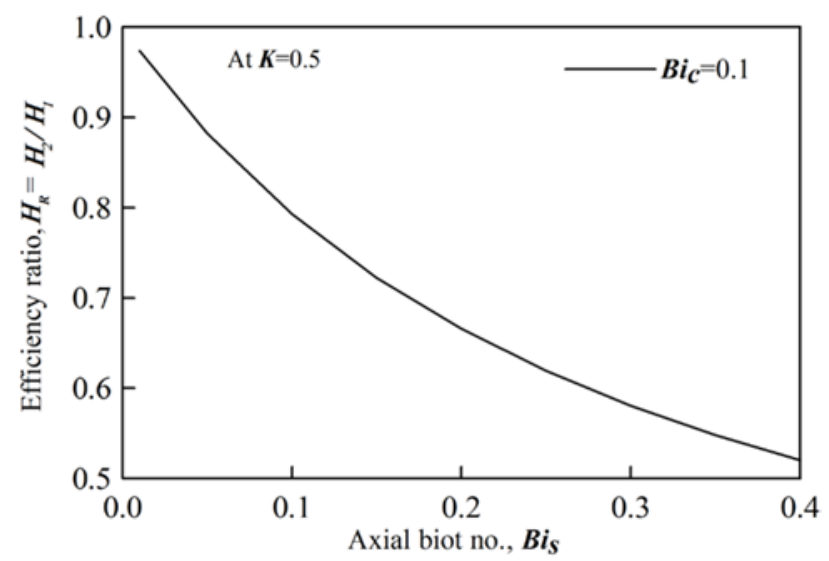

Fig. 4 Plot of efficiency ratio with $B i_{s}$ at $K=0.5$ and $b / a=1.2$ 
The variation of efficiency with axial Biot number for different conductivity ratio $(K=0.25,0.50$ and 1.00$)$ is plotted in Fig. 5 (a-c). The results are reported for fin having aspect ratio, $b / a=1.2$. It is observed that increase in axial Biot number reduces the fin efficiency. Each of these plots are reported for a range of $B i_{c}$ values. Results reveal that efficiency for orthotropic fin increases with increase in orthotropic nature of the fin material, (i.e. decrease in $K$ value) and in all the cases, more efficient are the fins having larger contact Biot number, $B i_{c}$. The effect of aspect ratio on fin efficiency is reported at $B i_{c}=0.1$ in Fig. $6(\mathrm{a}-\mathrm{c})$ for the same set of values of different conductivity ratio. Fig. 5-6 reveal that short annular orthotropic fins with lower $K$ values, least axial Biot number and large contact Biot numbers yield the best efficiency. The effectiveness of annular fin is also an important performance parameter. The effect of thermal conductivity ratio, axial and contact Biot number and aspect ratio on the effectiveness is studied and reported in Figs. 7-8.
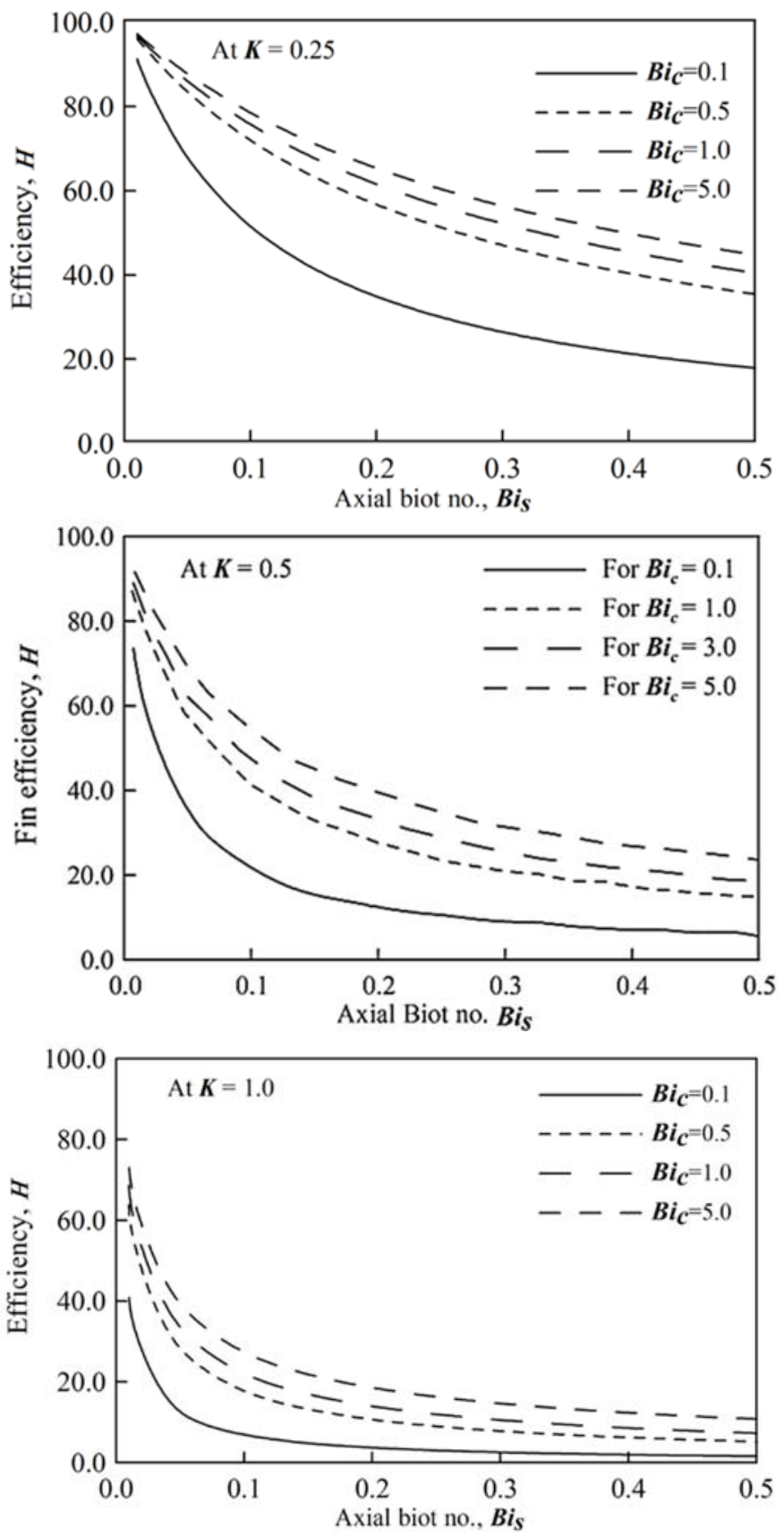

Fig. 5 Efficiency variations with Axial Biot number $\left(B i_{s}\right)$ for different Contact Biot number $\left(B i_{c}\right)$ at different $K$
The variation of effectiveness with axial Biot number is plotted in Fig 7 (a-c) for different conductivity ratio $(K=0.25,0.50$ and 1.00$)$. Each plot reports the variation of effectiveness with axial Biot number for fin with aspect ratio $b / a=1.2$ for a range of $B i_{c}$. Fig. 7 (a-c) indicates that for insulated tip condition, as $K$ is reduced, thus increasing the orthotropic nature of the fin, effectiveness increases and for $B i_{s}$ at 0.01 , as $K$ is decreased, the $\varepsilon$ for all the values of $B i_{c}$ attain a constant value. The variation of effectiveness with axial Biot number for different aspect ratio of the fin is plotted in Fig. $8(\mathrm{a}-\mathrm{c})$. The results are reported at $B i_{c}=0.1$. Orthotropic annular fins with least axial Biot number and large contact Biot number are reported to be most effective for heat transfer. This is because of larger area available with longer fin for heat transfer. Although, in such cases, fin efficiency is lower with larger aspect ratio, it can be opted under conditions demanding larger amount of heat transfer.
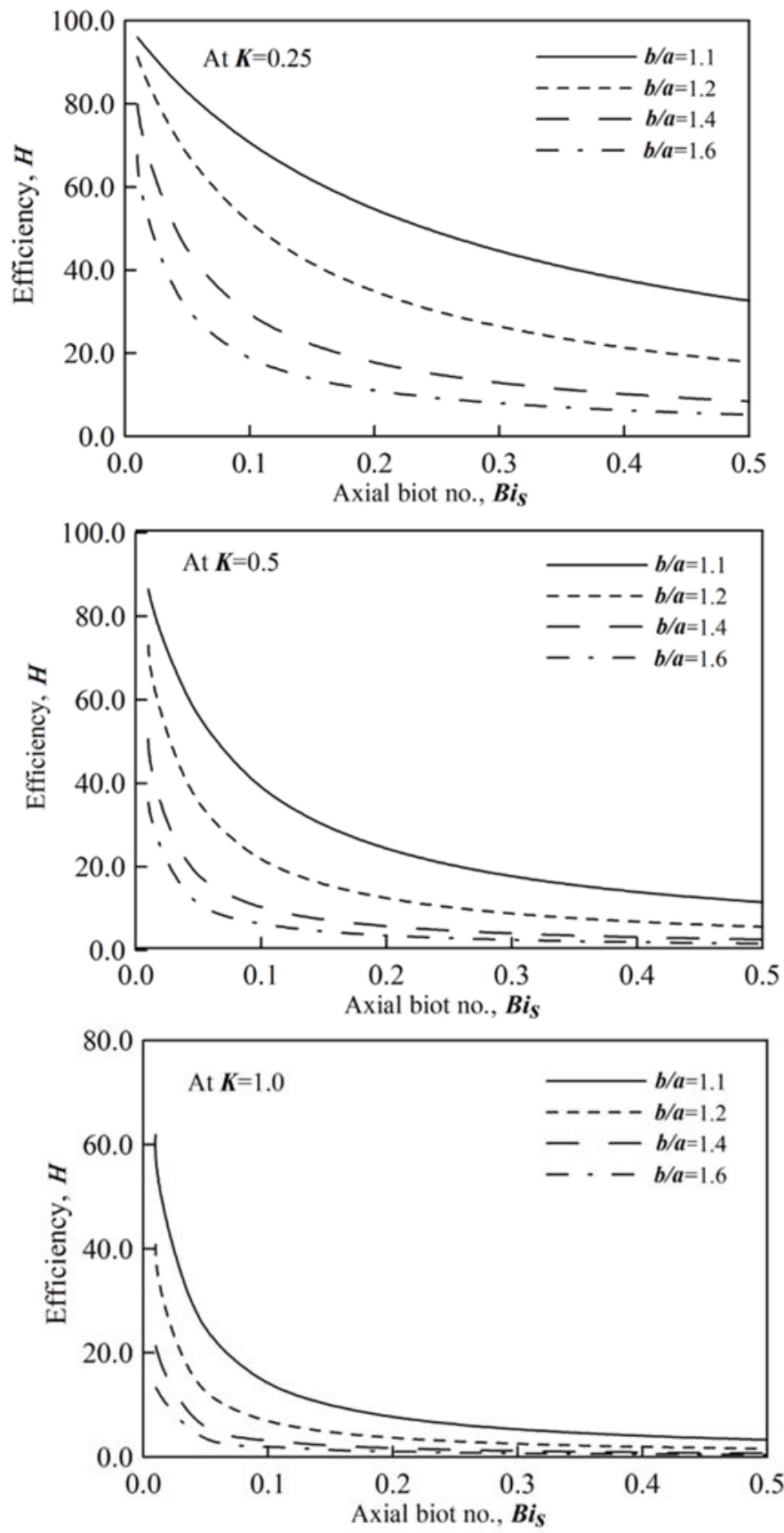

Fig. 6 Efficiency variations with Axial Biot number $\left(B i_{s}\right)$ for different Contact Biot number $\left(B i_{c}\right)$ at different $b / a$ ratio 

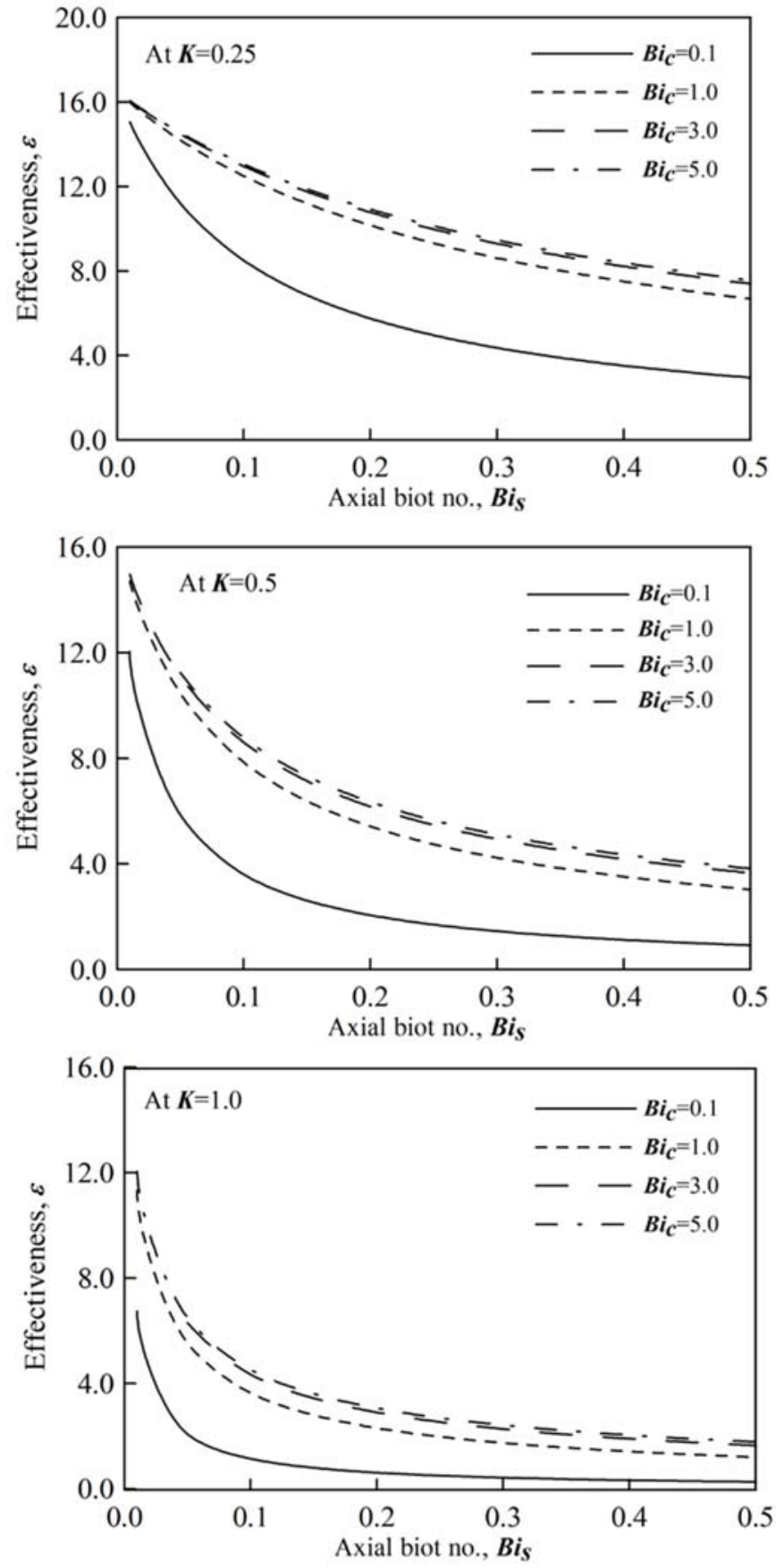

Fig. 7 Effectiveness variations with Axial Biot number $\left(B i_{s}\right)$ for different Contact Biot number $\left(B i_{c}\right)$ at different $K$

\section{CONCLUSION}

The present work reports the thermal performance of annular fins with orthotropic material properties based on a two-dimensional formulation. The governing equation in two dimensions is solved by finite difference method. First, the contour plots of the solution obtained in terms of temperature distribution along the radius as well as the thickness is reported. The contour plots reveal the necessity of comparing the performance of annular fins obtained from two dimensional study with one dimensional fin performance. The reported results point towards the overestimate of fin performance based on one dimensional studies.
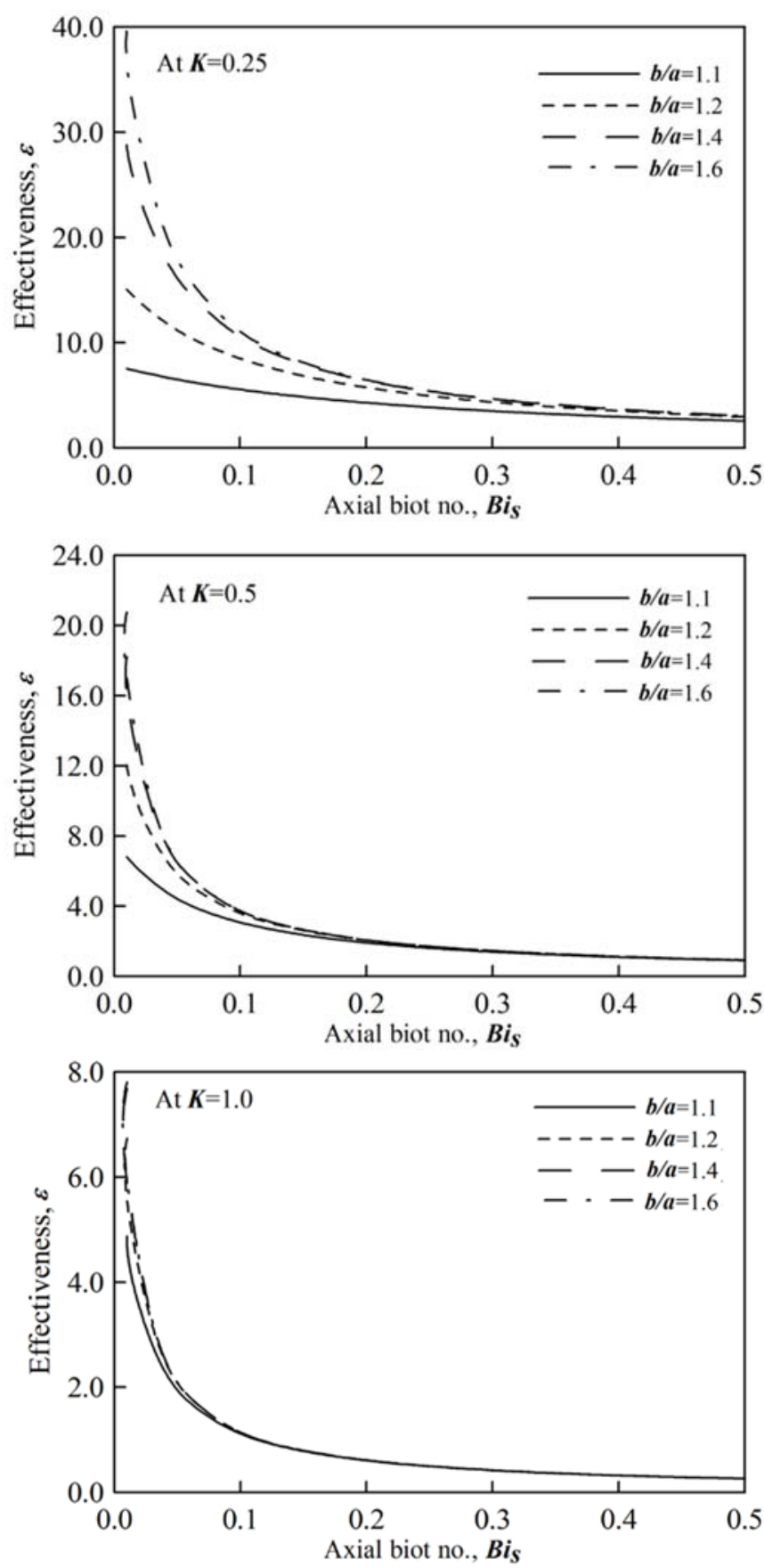

Fig. 8 Effectiveness variations with Axial Biot number $\left(B i_{s}\right)$ for different $b / a$ ratio at different $K$

Fin performance, in terms of fin efficiency and effectiveness, is reported under different design parameters. Under insulated tip conditions and different contact resistance values at the fin base, the effect of variation of Axial Biot number and aspect ratio of the fin on fin performance is plotted for fins having orthotropic material response with $K=0.25,0.50$ and 1.00. The plots serve as design data for calculating heat transfer for annular fins having several complexities which render the model to be more close to practical applications particular to those conditions where one dimensional study over predicts the performance of the fin. 


\section{NOMENCLATURE}

$\begin{array}{ll}b / a & \text { Aspect ratio } \\ B i_{c} & \text { Contact Biot number } \\ B i_{e} & \text { Tip Biot number } \\ B i_{s} & \text { Axial Biot number } \\ h & \text { Convection heat transfer coe cient for the top surface } \\ h_{c} & \text { Convection heat transfer coe cient for the contact surface } \\ h_{e} & \text { Convection heat transfer coe cient for the tip surface } \\ H & \text { Efficiency of the fin } \\ K & \text { Thermal conductivity ratio }\left(\mathrm{K}_{z} / \mathrm{K}_{\mathrm{r}}\right)^{0.5} \\ K_{z} & \text { Thermal conductivity along the axial direction } \\ K_{r} & \text { Thermal conductivity along the radial direction } \\ Q & \text { Heat transfer from the fin } \\ R_{l} & \text { Inner radius of the fin } \\ R_{2} & \text { Outer radius of the fin } \\ \delta_{0} & \text { Fin thickness } \\ \Phi & \text { Dimensionless temperature } \\ \varepsilon & \text { Effectiveness of the fin }\end{array}$

\section{REFERENCES}

Yovanivich, M. M, Culham, J. R., and Lemczyk, T. F., 1988, "Simplified Solutions to Circular Annular Fins with Contact Resistance and End Cooling," International Journal of Thermophysics, 2(2), 152-157. http://dx.doi.org/10.2514/3.79

Mustafa, M. T., Zubair, Syed M., and Arif, A. F. M., 2011, "Thermal Analysis of Orthotropic Annular Fins with Contact Resistance : A Closed Form Analytical Solution," Applied Thermal Engineering, 31(5), 937945.

http://dx.doi.org/10.1016\%2Fj.applthermaleng.2010.11.017

Campo, A., and Acosta-Iborra, A., 2009, "Approximate Analytic Temperature Distribution and Efficiency for Annular Fins of Uniform thickness," Int. J. of Thermal Sciences, 48(4), 773-780.

$\underline{10.1016 / j . i j t h e r m a l s c i .2008 .05 .012}$

Hatami, M., and Ganji, D. D., 2014, "Thermal Behaviour of Longitudinal Convective - Radiative Porous Fins with Different Section Shapes and Ceramic Materials ( $\mathrm{SiC}$ and $\mathrm{Si}_{3} \mathrm{~N}_{4}$ )," Ceramics International 40(5), 6765-6775.

http://dx.doi.org/10.1016/j.ceramint.2013.11.140
Aziz, A., and Rahman, M. M., 2009, "Thermal Performance of a Functionally Graded Radial Fin," International Journal of Thermophysics, 30, 1637-1648. http://dx.doi.org/10.1007/s10765-009-0627-x

Gaba, V. K., Tiwari, A. K., and Bhowmick, S., 2014, "Thermal Performance of Functionally Graded Parabolic Annular Fins Having Constant Weight," Journal of Mechanical Sciences and Technology, 28(10), 4309-4318. http://dx.doi.org/10.1007/s12206-014-0945-1

Aziz, A., and Lopez, R. J., 2011, "Convection-Radiation from a Continuously Moving Variable Thermal Conductivity Sheet or Rod Undergoing Thermal Processing," International Journal of Thermal Sciences, 50(8), 1523-1531. http://dx.doi.org/10.1016/j.ijthermalsci.2011.03.014

Aziz, A., and Khani, F., 2011, "Convection-Radiation from a Continuously Moving Fin of Variable Thermal Conductivity," Journal of the Franklin Institute 348(4), 640-651.

http://dx.doi.org/10.1016/j.jfranklin.2011.01.008

Torabi, M., Yaghoobi, H. and Aziz, A., 2012, “Analytical Solution for Convective - Radiative Continuously Moving Fin with Temperature-

Dependent Thermal Conductivity," International Journal of Thermophysics, 33, 924-941. http://dx.doi.org/10.1007/s10765-012-1179-z

Aziz, A., Mujahid, M., and Abu-Abdou, K., 1993, "Thermal Performance of Annular Fins of Arbitrary Profile Subjected to Periodic Base and Environment Temperature," J. King Saud University, 5(1), 105-122.

Kang, H. S., and Look, D. C., 1997, "Two Dimensional Trapezoidal Fins Analysis, Computational Mechanics," Computational Mechanics, 19, 247-250.

http://dx.doi.org/10.1007/s004660050173

Lin, C., and Jang, J., 2002, “A Two-Dimensional Fin Efficiency Analysis of Combined Heat and Mass transfer in Elliptic Fins," Int. J. Heat and Mass Transfer, 45, 3839-3847.

http://dx.doi.org/10.1016/S0017-9310(02)00086-8

Gaba, V. K., Tiwari, A. K., and Bhowmick, S., 2015, "A Parametric Study of Functionally Graded Rotating Annular Fin," Procedia Engineering 127, 126-132.

http://dx.doi.org/10.1016/j.proeng.2015.11.436 